\title{
Avaliação das Estratégias de Comercialização do Milho em MS Aplicando o Analytic Hierarchy Process (AHP) ${ }^{1}$
}

\author{
João Gilberto Mendes dos Reis², Oduvaldo Vendrametto ${ }^{3}$, \\ Irenilza de Alencar Naas ${ }^{4}$, Lucio Tadeu Costabile ${ }^{5}$ e \\ Sivanilza Teixeira Machado ${ }^{6}$
}

Resumo: Os produtores de milho precisam decidir sobre qual a melhor alternativa para comercialização do produto: vender antes da colheita, no momento da colheita, no mercado futuro ou armazenar para vender na entressafra. Entretanto, essa nem sempre é uma tarefa fácil já que depende de diversas variáveis que afetam diretamente essa decisão. Neste estudo, foram analisados dados da produção de milho internacional e brasileira e buscou-se identificar qual a melhor estratégia de comercialização de milho para os produtores de Mato Grosso do Sul (MS) considerando quatro variáveis de decisão em conjunto: logística, preço, produtividade e disponibilidade de produto. Essa análise multicritério foi realizada adotando-se a metodologia do Analytic Hierarchy Process (AHP) com o uso do software Expert Choice ${ }^{\circledR}$ v. 11. Os resultados indicaram que a melhor decisão para o produtor de milho de MS seria vender o produto na entressafra e também apontaram que a logística foi o critério de maior peso na tomada de decisão $(0,467)$.

Palavras-chaves: AHP; Produção de milho; Logística de grãos; Mato Grosso do Sul.

Abstract: Corn producers need to find the best alternative to sell the production; selling before harvest, during the harvest, in the future market or store to sell in the off-season period. However, this is not an easy task because the crop is affected by several variables. In this study, we analyzed international and Brazilian corn production data to find out the best strategy of corn commercialization for Mato Grosso do Sul State (Brazil) producers.

1. Data de submissão: 12 de maio de 2015. Data de aceite: 15 de janeiro de 2016.

2. Universidade Paulista, São Paulo, São Paulo/Brasil. E-mail: jgilbertomreis@unip.br

3. Universidade Paulista, São Paulo, São Paulo/Brasil. E-mail: oduvaldov@uol.com.br

4. Universidade Paulista, São Paulo, São Paulo/Brasil. E-mail: irenilza@gmail.com

5. Universidade Paulista, São Paulo, São Paulo/Brasil. E-mail: luciotc@terra.com.br

6. Universidade Paulista, São Paulo, São Paulo/Brasil. E-mail: sivateixeira@yahoo.com.br 
We considered four variables alltogether: logistics, price, productivity and product availability. The multicriteria analysis was done using the Analytic Hierarchy Process (AHP) using the software Expert Choice (C) v.11. The results indicated that the best decision for growers in Mato Grosso do Sul is selling the corn production in the offseason. Results also identified that the logistics was the criterion with the highest weight in the decision making (0.467).

Key-words: AHP; Corn production; Grain logistics; Mato Grosso do Sul State.

DOI - http://dx.doi.org/10.1590/1234-56781806-9479005401007

Classificação JEL: Q13.

\section{Introdução}

A produção de alimentos representa um dos maiores desafios da atualidade e do futuro. Segundo a última revisão da Organização das Nações Unidas (ONU, 2015) a população mundial está estimada em 7,349 bilhões de pessoas com previsão de atingir o contingente de 9,725 bilhões em 2050, o que torna crucial a produção de alimentos. O Brasil, pela importância que passou a ter em função da sua evolução econômica, sendo a sétima economia mundial com um Produto Interno Bruto (PIB) de 2,2 trilhões de dólares (WORLD BANK, 2014), tem responsabilidades, desafios e oportunidades neste novo cenário. O País ocupa posição relevante na produção de alimentos oriundos do agronegócio, em culturas como milho, soja e café. Entretanto, a logística é um dos maiores problemas da produção de brasileira de alimentos e, mais especificamente, de grãos.

Utilizando-se de estruturas compartilhadas para os diversos tipos de grãos, há no Brasil um déficit de áreas de armazenamento e veículos de transporte, o que aumenta os custos logísticos e as perdas na produção. Além disso, são incluídas altas tarifas de pedágio e estradas em condições precárias (MARTINS et al., 2005; CORRÊA e RAMOS, 2010; PATINO et al., 2013). Os centros de produção são distantes dos portos e a exportação requer custos logísticos que reduzem a competitividade e principalmente o ganho do produtor (CORREAA e RAMOS, 2010). Ainda, a rede de armazéns seria insuficiente se toda safra fosse armazenada ao mesmo tempo (PATINO et al., 2013; REIS et al., 2013).

Para enfrentar esses problemas os produtores precisam identificar formas de comercializar os seus produtos a preços que tragam uma lucratividade, mesmo com tantas restrições logísticas apresentadas, que encarecem os custos de comercialização e produção. Uma dessas alternativas consiste na implantação de áreas de armazenagem próximas às áreas de produção para comercializar o produto em momentos mais favoráveis, quando o seu preço é maior e o custo da infraestrutura de transportes é menor. Todavia, Cruz Junior et al. (2011) identificaram que os produtores fazem pouco uso de comercialização de mercados futuros, seja pelo excesso de confiança, ou pela falta de informação.

No caso específico do milho, existe um agravante que é compartilhamento da infraestrutura logística de transporte e armazenagem com a soja. Em Mato Grosso do Sul, por exemplo, o milho é plantado na entressafra da soja e precisa ser escoado totalmente antes que ela comece a ser colhida. 
Essa condição justifica o resultado do estudo de Moreira et al. (2014) que avaliaram retornos e riscos para comercialização do milho por cooperativas (cerealistas) em três cenários distintos utilizando a metodologia econômica Value at Risk (VaR) e concluíram que para essas cooperativas a melhor estratégia é comprar o milho do produtor e vender imediatamente.

Esse cenário levanta questões ao produtor de milho: Como melhorar a lucratividade sobre a sua produção? Existe um cenário mais adequado para comercialização do produto que represente maior lucratividade? Como decidir em que momento vender considerando mais que uma variável em conjunto? A infraestrutura logística pode realmente ser considerada um gargalo para a comercialização do milho?

Para responder essas perguntas este trabalho buscou avaliar o melhor cenário para comercialização do milho, utilizando a perspectiva do produtor rural de Mato Grosso do Sul. Especificamente, o trabalho tem como objetivos verificar se o melhor momento para venda do milho para o produtor de MS seria: (1) antes da colheita, (2) no momento da colheita, (3) na entressafra ou (4) no mercado futuro. Além disso, objetivou-se estudar qual a influência dos critérios Logística (L), Preço (P), Produtividade (PP) e Disponibilidade (D) na decisão de comercialização do milho.

Uma análise utilizando o modelo de decisão Analitic Hierarchy Process (AHP) desenvolvido por Saaty (1980) foi conduzida utilizando dados coletados junto a produtores de MS durante o $2^{\mathrm{o}}$ semestre de 2013 e $1^{\circ}$ Semestre de 2014 e nas referências bibliográficas apresentadas ao longo do presente artigo. Para gerar a árvore de dependência e analisar os pesos das comparações paritárias utilizou o software Expert Choice ${ }^{\circledR}$ v.11.

\section{Produção brasileira de milho}

A produção do milho é relativamente dispersa no Brasil. Segundo o Ministério da Agricultura, Pecuária e Abastecimento (MAPA, 2013) entre os principais estados produtores encontram-se o Paraná $\left(22,610^{6} \mathrm{t}\right)$, Mato Grosso (23,5 10 $\mathrm{t}$ ), Minas Gerais $\left(9,510^{6} \mathrm{t}\right)$, Goiás $\left(9,410^{6} \mathrm{t}\right)$, Mato Grosso do Sul $\left(8,610^{6} \mathrm{t}\right)$ e Rio Grande do Sul $\left(6,910^{6} \mathrm{t}\right)$, que responderam, em 2013, por cerca de $80 \%$ da produção nacional. Considerando por regiões, o Centro-Oeste e Sul detêm as maiores, com $42 \%$ $34,1 \%$, respectivamente. A área agrícola brasileira, ocupada pelo plantio do milho na safra de 2012/13, cresceu para $16,710^{6}$ ha, devendo chegar, na safra de 2022/23, em $21,610^{6}$ ha. Ao mesmo tempo, a produção cresceu de 71,2 106 t em 2012, para 80,7 106 t em 2013 (MAPA, 2013). Os estados do Paraná e Mato Grosso são aqueles que detêm as maiores áreas de plantio para o milho.

As exportações de milho de $18.10^{6} \mathrm{t}$, em 2013, deverão crescer para $25.10^{6} \mathrm{t}$ na safra de 2022/23. Para manter o consumo interno projetado de aproximadamente $6210^{6} \mathrm{t}$ e garantir um volume aceitável de estoques finais e o nível de exportações esperado, a produção foi estimada em $9310^{6}$ t para 2023 (MAPA, 2013). Ainda neste contexto, de acordo com o International Grains Council (IGC, 2015) a plantação da segunda safra brasileira deve continuar a crescer em virtude da facilidade de usar a estrutura de plantio da soja. Desta forma, segundo o órgão, esta segunda safra aumentou em relação ao plantio exclusivo do milho. Esse cenário é o resultado direto do aumento de demanda internacional do milho, que continuará em crescimento nos próximos cinco anos. A Figura 1 apresenta a produção e consumo de milho na safra 2014/15 e as projeções de demanda e consumo até a safra 2020/21. 
Figura 1. Projeção produção e consumo mundial de milho

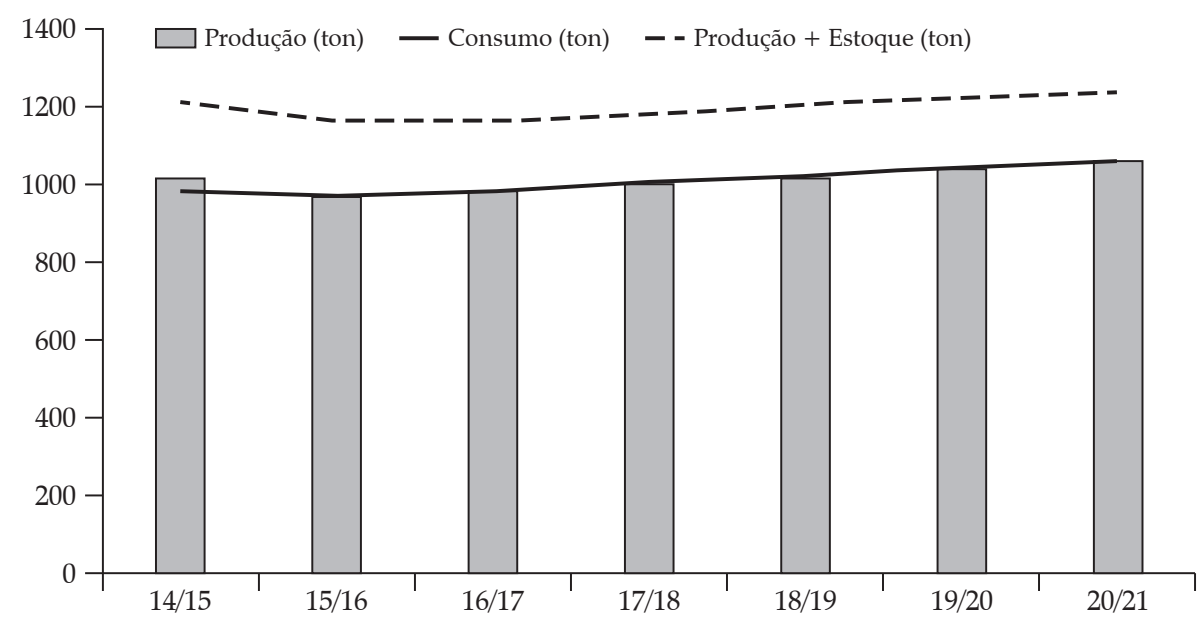

Fonte: Elaborado pelo autores com dados do International Grains Council (IGC, 2015).

O cultivo do milho no Brasil tem duas finalidades: atender a demanda interna, sendo usado como ração para alimentação de animais (suínos, bovinos e de frango), ou industrializado para consumo humano e, neste caso, a produção é suficiente para o mercado interno. O excedente é exportado como commodity, obedecendo as cotações internacionais. $\mathrm{O}$ plantio principal ocorre nos meses de setembro (MT e MS) a novembro (nos outros estados), seguindo a variação do regime de chuvas que se inicia na primavera. Simultaneamente, planta-se soja, arroz, feijão, entre outras culturas. A colheita em MT e MS é realizada em janeiro e, nos outros estados, até o período de março/abril. A retirada desta safra é seguida por uma segunda etapa de plantio, conhecida como safrinha, pelas características sazonais. Esta segunda safra, plantada no local em que é colhida a soja, se beneficia do resíduo de fertilizantes no solo, que provoca uma melhora de produtividade e se constitui em vantagem adicional à produção desse cereal. Países como o Brasil, com áreas disponíveis ao plantio, podem aumentar sua produção utilizando para o milho áreas ocupadas com outras culturas. Entretanto, estas iniciativas podem gerar desbalanceamento no que tange a valores do grão no mercado. A produção sem as devidas precauções pode ferir princípios quanto à sustentabilidade e valores nutricionais de "saudabilidade" do produto. A expectativa de lucro com a exportação favorece a ampliação de área para plantio com desmatamento ou uso de pastagens.

Neste contexto da produção de milho brasileira, a decisão dos Estados Unidos em produzir etanol e adicioná-lo na gasolina para veículos afetou diretamente o mercado de produção de milho do País. A produção americana de etanol tem duplicado a cada cinco anos, como pode ser visualizado na Tabela 1.

Tabela 1. Crescimento da produção de milho e de etanol nos EUA

\begin{tabular}{ccc}
\hline Ano & Quantidade de Milho* & Produção Total (\%) \\
\hline $2002 / 2003$ & 28 & 11,5 \\
$2007 / 2008$ & 76 & 23,0 \\
$2012 / 2013$ & 118 & 43,0 \\
\hline${ }^{*} 10^{6}$ t. & \\
Fonte: Adaptado de Good (2013) e RFA (2014).
\end{tabular}


O efeito desta decisão é um aumento nos preços das rações e dos alimentos derivados de milho, gerando a necessidade de aumentar a produção em diversos países comercializadores, para atender a demanda mundial a preços aceitáveis. A decisão norte-americana de produzir etanol do milho aumentou significativamente a demanda desse produto no âmbito mundial. Consequentemente, fornecedores deste insumo no mundo voltaram para demanda do mercado americano, muitas vezes deixando os mercados internos em crise, por falta de produto. A produção de aves e suínos brasileira, dependente de ração produzida de milho foi impactada por essa nova contingência de mercado.

\section{Logística}

Apesar do avanço da produção de grãos no País, o desenvolvimento da infraestrutura de transporte não acompanhou no mesmo ritmo. Segundo a Confederação Nacional de Transporte
(CNT, 2014), a deficitária estrutura disponível está apoiada no transporte rodoviário de cargas e é responsável por mais de $61,1 \%$ do transporte realizado no País, enquanto o ferroviário, também sucateado, responde por 20,7\%. A deficiência do sistema de transportes representa significativo item de custos para o Brasil e é responsável pela maior redução dos lucros do produtor. Para exemplificar o que isso representa em custo para o País, a Tabela 2 apresenta uma comparação entre o custo de transporte de grãos, entre o Brasil e os Estados Unidos, para distâncias similares.

O transporte americano de grãos é realizado por hidrovias e ferrovias (96\%), a custos de 27,47 e 35,29 US\$/t, respectivamente. No Brasil, por outro lado, o transporte por caminhões custa $146 \%$ e $92 \%$ a mais, respectivamente. Esta deficiência afeta diretamente a competitividade e a lucratividade da produção de grãos brasileiros. Acrescenta-se, ainda, as perdas ocorridas em todo o processo da pós-colheita, em que o transporte dentro da fazenda tem importante participação. O estado de Mato Grosso é uma das exceções

Tabela 2. Custo do frete Brasil a China versus EUA a China

\begin{tabular}{|c|c|c|}
\hline Dados & Brasil & EUA \\
\hline Trajeto interior & Maracaju/MS a Santos/SP & Champaign/IL a Nova Orleans/LA \\
\hline Distância interior (km) & $1.094,7$ & $1.277,3$ \\
\hline Distância marítima $(\mathrm{km})$ & $20.362,6$ & $18.513,2$ \\
\hline Distância marítima (dia) & 32 dias e 15 horas & 29 dias e 18 horas \\
\hline Caminhão & $\$ 67,81$ & -- \\
\hline Ferrovia & -- & $\$ 35,29$ \\
\hline Navegação interior & -- & $\$ 27,47$ \\
\hline Trajeto Internacional & Porto de Santos a Porto de Shangai & Porto de Nova Orleans a Porto de Shangai \\
\hline Marítimo & $\$ 42,25$ & $\$ 49,00$ \\
\hline \multicolumn{3}{|l|}{ Custo (US\$) } \\
\hline Total $^{(1)}$ & 110,06 & 84,29 \\
\hline Total $^{(2)}$ & 110,06 & 76,47 \\
\hline Diferença $^{(3)}$ & & $43,92 \%$ \\
\hline Custo/km(4) & 0,005 & 0,003 \\
\hline Diferença $^{(5)}$ & & $32,75 \%$ \\
\hline Diferença $^{(6)}$ & & $146,85 \%$ \\
\hline Diferença $^{(7)}$ & & $-13,80 \%$ \\
\hline
\end{tabular}

Notas: (1) Custo total frete considerando Brasil = caminhão + marítimo e EUA = ferroviário + marítimo; (2) Custo total frete considerando Brasil = caminhão + marítimo e EUA = hidroviário + marítimo; (3) Diferença do custo em percentual entre os menores fretes de cada país em relação ao menor preço dos EUA; (4) Custo por km considerando distância total percorrida (interior + marítimo) e menor valor de frete para cada país; (5) Diferença em percentual entre o custo por km de cada país; (6) Diferença em percentual entre o menor custo de frete interior de cada país; (7) Diferença em percentual entre o custo de frete marítimo de cada país.

Fonte: Salin (2013) e USDA/AMS (2014). 
Tabela 3. Perdas estimadas no transporte de milho entre a fazenda e o porto de embarque

\begin{tabular}{cccccc}
\hline Produto & $\begin{array}{c}\text { Produção 2012/2013 } \\
(\mathbf{1 0} \mathbf{t})\end{array}$ & $\begin{array}{c}\text { Preço médio pago } \\
\text { ao produtor } \\
(\mathbf{2 0 1 5})^{*}\end{array}$ & $\begin{array}{c}\text { Safra prevista 14/15 } \\
\left(\mathbf{1 0}^{\mathbf{6}} \mathbf{t}\right)\end{array}$ & $\begin{array}{c}\text { Valor total } \\
\text { da safra } \\
\text { (bilhões) }\end{array}$ & $\begin{array}{c}\text { Perdas no transporte } \\
\mathbf{( 0 , 2 5 \%} \text { a 4\%) } \\
\text { (milhões) }\end{array}$ \\
\hline Milho & $78.468,3$ & $\$ 8,40$ & 78,594 & $\$ 11,00$ & $\$ 27,51$ a $\$ 440,12$ \\
\hline
\end{tabular}

Notas: * Indicador de preços do milho ESALQ/BM\&F para saca de milho à vista em 11/05/2015 para saca de $60 \mathrm{~kg}$.

Fonte: Elaborado pelos autores a partir de dados de Semprebom (2009), Mapa (2013) e Conab (2015).

brasileiras, sendo que $60 \%$ da produção é transportada por trens e escoado via porto de Santos/ SP, $32 \%$ via hidrovia para escoamento na região e apenas $8 \%$ segue para exportação via caminhão, para os portos de Paranaguá/PR e São Francisco do Sul/SC (CAETANO e PRESSINOTT, 2013). O cenário vigente na produção e mobilidade de grãos apresenta infraestrutura deficiente. A produção se dá no interior do País, distante dos portos oceânicos e dos centros de consumo ou de manufatura. Os portos de escoamentos para exportação estão concentrados nas regiões Sul e Sudeste que recebe a grande produção do Centro-Oeste. Os principais consumidores de grãos, seja para alimentação de pessoas ou animais e industrialização, estão separados por grandes distâncias. $\mathrm{O}$ milho, por exemplo, é largamente consumido no Sul do País como alimento para animais, principalmente em Santa Catarina, onde se concentram os grandes produtores de frangos e suínos, além das indústrias frigoríficas responsáveis pelas exportações e consumo interno de carne.

Em quaisquer das situações existe um trade off. Os fatores favoráveis, como produtividade, recordes sucessivos de produção e espaço físico para crescimento estarão sempre em conflito com as distâncias a serem vencidas. Sendo as distâncias intangíveis do ponto de vista de mudanças é preciso, mesmo que a médio e longo prazos, que se encontre soluções mais eficientes para o desenvolvimento, melhores e menos custosas para o aproveitamento e retorno que esta riqueza pode oferecer. Veículos, vias, equipamentos de transportes, de carregamento e descarregamento, estão entre os fatores que levam o Brasil a significativas perdas de sua produção de grãos e lucratividade. O transporte, devido a sua repercussão, tem especial relevância entre os causadores dessa ineficiência e redução de competitividade da rede produtiva como um todo. A falta de dados claros sobre o volume de perdas de grãos favorece especulações para os mais diversos interesses. Estima-se que essa perda no transporte varie de $0,25 \%$ até $4 \%$ do volume total produzido (SEMPREBOM, 2009). Considerando-se os volumes totais de produção, as perdas são significativas, conforme indica a Tabela 3. Porém, a quantificação precisa destes valores de perdas nas cadeias produtivas de grãos mostra-se uma tarefa difícil, pois envolve processos desde a pós-colheita até o transporte rodoviário. Deliberador et al. (2013) estimou que em Mato Grosso do Sul as perdas com a soja no transporte estejam na casa de US\$17,5 milhões7. Deve-se observar também que o Estado é grande produtor de milho, o que agrava ainda mais esse número. Há que se observar, também, situações em que há operações de transbordos, incrementando ainda mais as estimativas.

Todavia, faltam estudos que mensurem esses prejuízos e possibilitem a criação de modelos que permitam estimar a perda de grãos durante as operações de transporte. Atualmente, como não se consegue estabelecer com melhor precisão esses valores, os agentes envolvidos com a cadeia produtiva não implementam soluções para sua eliminação.

Chinelato, Cruz e Ziviani (2011) afirmam que ausência de infraestrutura logística de qualidade nas estradas, portos e aeroportos brasileiros afetam a competitividade e os desperdícios ao longo das cadeias produtivas.

Para uma população mundial crescente é inaceitável que ocorram perdas de grãos devido a

7. Com base na cotação média do dólar em 2012. 
condições de transporte e infraestrutura inadequadas. A perda de grãos durante o transporte gera impactos ambientais e trazem problemas sanitários às diversas cidades envolvidas no trajeto deste transporte. Entretanto, o maior impacto da infraestrutura logística é relativo à competitividade das cadeias produtivas de grãos, precisando ser considerada na tomada de decisão de comercialização das commodities agrícolas e, no presente estudo, mais especificamente, do milho.

\section{Metodologia}

\subsection{Local e procedimentos da pesquisa}

O presente estudo foi conduzido utilizando dados da produção de milho internacional e brasileira, com enfâse na produção do estado de Mato Grosso do Sul (MS). O Estado tem população estimada em 2014 pelo Instituto Brasileiro de Geografia e Estatística (IBGE) de 2.619.657 habitantes, com área de $357.147 \mathrm{~km}^{2}$, que gera densidade de 6,86 hab/ $\mathrm{km}^{2}$ em seus 79 municípios (IBGE, 2015). A produção de milho no Estado em 2013 foi de 6,573 milhões de toneladas, correspondendo a $\mathrm{R} \$ 907$ milhões, com rendimento médio de 5,2 toneladas por hectare. As principais cidades produtoras são Maracaju (5ํํำ no cená-

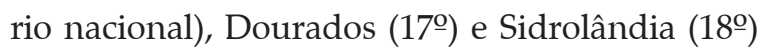
(IBGE, 2014). O Estado é o quinto maior produtor de milho do País (MAPA, 2013).

Foram utilizados os dados relativos à cadeia produtiva do milho, disponíveis em órgãos nacionais como Mapa (2013) e IBGE (2014) e internacionais como USDA (2014), FAO (2014) e IGC (2014). Além disso, foram coletados dados junto aos produtores do estado. Essa coleta de dados foi realizada entre o segundo semestre de 2013 e o primeiro semestre 2014. A análise preliminar dos dados permitiu selecionar quatro estratégias/alternativas, que orientam os proprietários rurais no momento de vender a safra do milho: (1) antes da colheita, (2) durante a colheita, (3) armazenar para vender na entressafra ou (4) vender no mercado futuro.

\subsection{Utilizando o método de decisão multicritério do Analytic Hierarchy Process}

O Analitic Hierarchy Process (AHP) foi um processo desenvolvido por Thomas L. Saaty nos anos 1970 e consiste em análise multicriterial que mensura, por meio de comparações paritárias e estabelece escalas de prioridade, com base no julgamento de especialistas sobre determinado tema (SAATY e SHANG, 2011), possibilitando assim a tomada de decisão quando existem múltiplos critérios envolvidos. O AHP é uma ferramenta quantitativa que auxilia a priorizar problemas e variáveis baseadas em critérios e alternativas relevantes (SURESHCHANDAR e LEISTEN, 2006). Esta técnica tem sido utilizada para resolver diversos problemas logísticos e de estratégia. Hong e Xiaohua (2011) aplicaram este processo para determinar a melhor localização de um centro logístico de emergência, considerando critérios sociais, ambientais, econômicos e técnicos. Peng (2012) utilizou o AHP para selecionar prestadores de serviço logístico, por meio de critérios como custo, eficiência, qualidade e tecnologia. García et al. (2014) utilizaram a AHP para avaliar localizações de armazéns para alimentos agrícolas. Divahar e Sudhahar (2012) utilizaram a análise hierárquica para determinar o melhor provedor de serviços logístico para realizar operações de logística reversa.

Para utilizar o AHP é necessário decompor o problema em alguns passos, conforme estabelecido por (SAATY, 2008). Desse modo, (1) definiu-se o problema e o tipo de conhecimento necessário para solucioná-lo; (2) estruturou-se a árvore de decisão do objetivo a ser alcançado, passando pelos critérios a serem avaliados para alcançar as possíveis alternativas, em uma estrutura hierárquica; (3) construiu-se uma matriz para comparação paritária, analisando um nível superior com os respectivos níveis imediatamente inferiores a este; e (4) foram utilizadas as prioridades obtidas das comparações para determinar os pesos e prioridades do nível imediatamente inferior. 


\subsection{Definição do problema}

O objetivo da AHP foi determinar qual o melhor momento da venda da produção de milho, considerando o cenário do produtor rural de MS. Os critérios que respaldaram a decisão foram: Logística (L) custos de transporte e armazenagem; Preço $(\mathrm{P})$ do produto no mercado futuro, no mercado à vista da Bolsa de Mercadorias e Futuros, e no mercado local regional; Produtividade (PP) que consistiu no grau de mecanização utilizado na lavoura, no clima da região, nos tipos de solo em MS e os insumos da cadeia produtiva; e Disponibilidade (D) de produto no mercado no momento da venda. Para definir estes critérios e pesos a serem adotados foram selecionadas referências bibliográficas que suportam as escolhas, além de dados coletados junto a produtores para cada um dos critérios (Tabela 4).

\subsection{Estruturação da análise multicriterial}

A metodologia AHP utiliza a comparação paritária entre cada um dos critérios, subcritérios, alternativas e correlação entre níveis usando uma escala denominada nominal (DENG et al., 2014), conforme indicado na Tabela 5. Estas comparações feitas com a finalidade de determinar os

Tabela 4. Descrição da literatura utilizada para auxiliar na atribuição dos pesos dos critérios nas comparações paritárias

\begin{tabular}{|c|c|c|c|c|}
\hline Fonte & Logística & Preço & Produtividade & $\begin{array}{c}\text { Disponibilidade } \\
\text { de Produto }\end{array}$ \\
\hline Miljkovic et al. (2000) & $\mathrm{X}$ & & & \\
\hline Abitante (2008) & & $x$ & & $x$ \\
\hline Correa e Ramos (2010) & $x$ & & & \\
\hline Sousa et al. (2010) & & $x$ & & \\
\hline Zhang et al. (2010) & & $x$ & & \\
\hline Ciaian et al. (2011) & & $x$ & & \\
\hline Dyer e Taylor (2011) & & $x$ & & \\
\hline Gardebroek e Hernandez (2013) & & $x$ & & \\
\hline Mapa (2013) & & & $x$ & \\
\hline Quintino e David (2013) & & $x$ & & \\
\hline Reis et al. (2013) & $x$ & & & \\
\hline Salin (2013) & $x$ & & & \\
\hline Abramilho (2014) & & & $x$ & \\
\hline Advfn (2014) & & $x$ & & \\
\hline Beckmann e Czudaj (2014) & & $x$ & & \\
\hline CIA (2014) & $x$ & & & \\
\hline FAO (2014) & & & $x$ & \\
\hline IGC (2014) & & & $x$ & $x$ \\
\hline Peri et al. (2014) & & $x$ & & \\
\hline USDA (2014) & $x$ & & $x$ & $x$ \\
\hline Produtores & $x$ & $x$ & $x$ & $x$ \\
\hline
\end{tabular}

Fonte: Elaborado pelo autores.

Tabela 5. Escala de comparação paritária dos critérios

\begin{tabular}{cc}
\hline Escala & Significado \\
\hline 1 & Igual importância \\
3 & Moderada importância \\
5 & Forte importância \\
7 & Muito forte importância \\
9 & Extrema importância \\
$2,4,6,8$ & Valores intermediários \\
\hline
\end{tabular}

Fonte: Adaptado de Saaty (2008). 
níveis de importância de cada critério e atributo comparando, por exemplo, um elemento $i$ com um elemento $j$ (GARCÍA et al., 2014), conforme apresentado em (1).

$$
A=\left[\begin{array}{cccc}
1 & a 12 & \ldots & a 1 n \\
a 21 & 1 & \ldots & a 2 n \\
\ldots & \ldots & \ldots & \ldots \\
a n 1 & a n 2 & \ldots & 1
\end{array}\right]
$$

Desta forma, o uso do AHP correlaciona os diversos critérios e procede com as comparações paritárias, identificando inconsistências nas análises. Ao efetuar o lançamento dos dados no sistema, se o analista especificar que $b>a \mathrm{e}$ $a>c$, logo espera-se que $b>c$, caso contrário, uma inconsistência é apontada nos cálculos pelo software. Assim a metodologia AHP estabelece um índice de inconsistência (KURKA, 2013; GARCÍA et al., 2014). Este índice de inconsistência é expressado matematicamente em (2). A inconsistência máxima admitida para garantir a confiabilidade na decisão escolhida é IC $<0,1$. Caso seja maior é necessário ajustar as comparações antes de prosseguir na análise dos critérios.

$$
\text { IC }=\frac{\lambda \operatorname{má} x-n}{n-1}
$$

Em que:

$\lambda$ máx = auto valor máximo;

$n=$ dimensão da matriz.

Portanto, a razão de consistência, segundo Costa (2002) e Castro (2014), pode ser dada por (3):

$$
R C=\frac{I C}{I R}
$$

Em que:

$R C=$ corresponde à razão de consistência das respostas dos decisores;

$I C=$ representa o índice de consistência e

$I R=$ corresponde ao índice aleatório, que foi calculado para matrizes quadradas de ordem $n$ pelo Laboratório Nacional Oak Ridge, Estados Unidos, sendo $1=0,00 ; 2=0,0 ; 3=0,58 ; 4=$ 0,$90 ; 5=1,12 ; 6=1,24$; e $7=1,32$.

Para determinar os pesos estabelecidos para cada um dos critérios, subcritérios e alternativas deve-se comparar mudanças entre a opções considerando o cenário preferido e o menos recomendado. Chun-Yu e Wen-Long (2012) esclarecem que, sempre que possível, médias aritméticas devem substituir os julgamentos dos especialistas para evitar erros por subjetividade das respostas. Para reduzir as inconsistências no modelo, procurou-se trabalhar com comparações quantitativas entre os pesos utilizando os dados coletados e a opinião dos produtores da região.

\section{5. Árvore de decisão}

Para a consecução do problema, desenvolveu-se uma árvore de decisão utilizando os critérios logística, preço, produtividade e disponibilidade do produto em que são efetuadas ponderações paritárias. As ponderações foram feitas por especialistas/produtores da região estudada e, quando não havia fundamentação ou houve dúvidas, foram utilizados dados das referências selecionadas, apresentadas na Tabela 4. A árvore de decisão (Figura 2) identifica o objetivo, os critérios e respectivos subcritérios e aponta as alternativas.

Determinadas as variáveis do modelo de decisão, os dados foram inseridos no software Expert Choice $^{\circledR}$ versão 11 (2014). 
Figura 2. Árvore de decisão para definir a estratégia de comercialização do milho

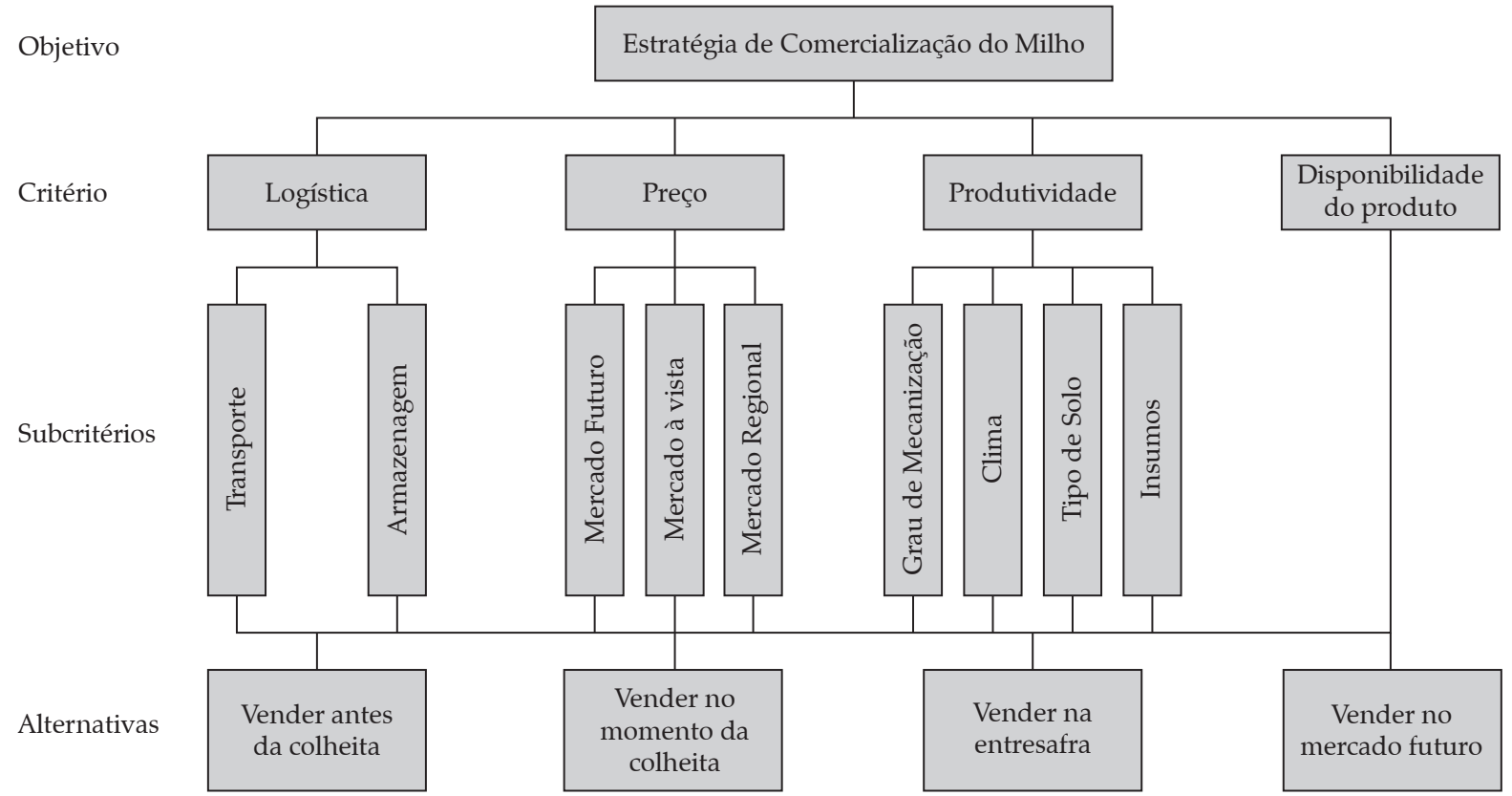

Fonte: Elaborado pelos autores.

\section{Resultados e discussão}

\subsection{Resultado geral}

O resultado geral mostra que o critério Logística teve o maior peso $(0,467)$, seguidos por Preço $(0,281)$, Produtividade $(0,162)$ e Disponibilidade do produto $(0,090)$, conforme indicado na Tabela 6. Além disso, permite con- cluir que a melhor opção para comercialização do milho pelos produtores de MS é vender na entressafra $(0,332)$.

\subsection{Critérios, subcritérios e alternativas}

Os pesos obtidos para cada critério e alternativa são apresentados na Tabela 7 e serão discutidos nos subtópicos seguintes.

Tabela 6. Resultado geral comparando critérios e alternativas com os respectivos pesos

\begin{tabular}{llll}
\hline \multicolumn{1}{c}{ Critérios } & Peso & \multicolumn{1}{c}{ Alternativa } & Peso \\
\hline Logística & 0,467 & Vender antes da colheita & 0,207 \\
Preço & 0,281 & Vender durante a colheita & 0,239 \\
Produtividade & 0,162 & Vender na entressafra & 0,332 \\
Disponibilidade do produto & 0,090 & Vender no mercado futuro & 0,221 \\
\hline
\end{tabular}

Fonte: Elaborada pelos autores. 
Tabela 7. Pesos dos critérios, subcritérios e alternativas

\begin{tabular}{|c|c|c|c|c|c|}
\hline \multirow[b]{2}{*}{ Critério } & \multirow[b]{2}{*}{ Subcritério } & \multicolumn{4}{|c|}{ Alternativas } \\
\hline & & $\begin{array}{l}\text { Vender antes } \\
\text { da Colheita }\end{array}$ & $\begin{array}{c}\text { Vender durante } \\
\text { a Colheita }\end{array}$ & $\begin{array}{l}\text { Vender na } \\
\text { Entressafra }\end{array}$ & $\begin{array}{c}\text { Vender no } \\
\text { Mercado Futuro }\end{array}$ \\
\hline \multirow{2}{*}{ Logística $(0,467)$} & Transporte $(0,500)$ & 0,163 & 0,065 & 0,559 & 0,212 \\
\hline & Armazenagem $(0,500)$ & 0,417 & 0,417 & 0,083 & 0,083 \\
\hline \multirow{3}{*}{ Preço $(0,281)$} & Mercado futuro $(0,528)$ & 0,094 & 0,165 & 0,308 & 0,433 \\
\hline & Bolsa de Mercadorias e Futuros $(0,333)$ & 0,096 & 0,169 & 0,368 & 0,368 \\
\hline & Valor regional $(0,140)$ & 0,094 & 0,165 & 0,433 & 0,308 \\
\hline \multirow{4}{*}{ Produtividade $(0,162)$} & Grau de mecanização $(0,072)$ & 0,200 & 0,567 & 0,100 & 0,133 \\
\hline & Clima $(0,570)$ & 0,083 & 0,417 & 0,417 & 0,083 \\
\hline & Insumos $(0,200)$ & 0,250 & 0,250 & 0,250 & 0,250 \\
\hline & Tipos de solo $(0,157)$ & 0,250 & 0,250 & 0,250 & 0,250 \\
\hline $\begin{array}{l}\text { Disponibilidade do } \\
\text { Produto no Mercado } \\
(0,090)\end{array}$ & & 0,181 & 0,064 & 0,605 & 0,151 \\
\hline
\end{tabular}

Fonte: Elaborada pelos autores.

\subsubsection{Logística}

A logística foi o critério que mais impactou na decisão de comercialização do milho $(0,467)$. Isto ocorre devido ao fato de o País ter uma malha logística deficitária, influenciada pelo modal de transporte rodoviário, que atua em distâncias superiores a 1.000 quilômetros. O País possui a quarta maior malha rodoviária do mundo, com $1.580 .964 \mathrm{~km}$, sendo que apenas $212.798 \mathrm{~km}$ de rodovias são pavimentadas (CIA, 2014). Essas vias, em sua maioria, pistas simples. Além disto, muitas estão em condições precárias e não comportam a demanda de veículos no período da safra.

O Brasil carece de áreas de armazenagem que dificulta o estoque do milho para venda no melhor momento como pode ser visto no levantamento da capacidade estática de MS (REIS et al., 2013). A Figura 3 apresenta a capacidade estática de armazenamento brasileira em relação à produção de grãos entre 2000/2011.

Figura 3. Capacidade estática versus produção de grãos

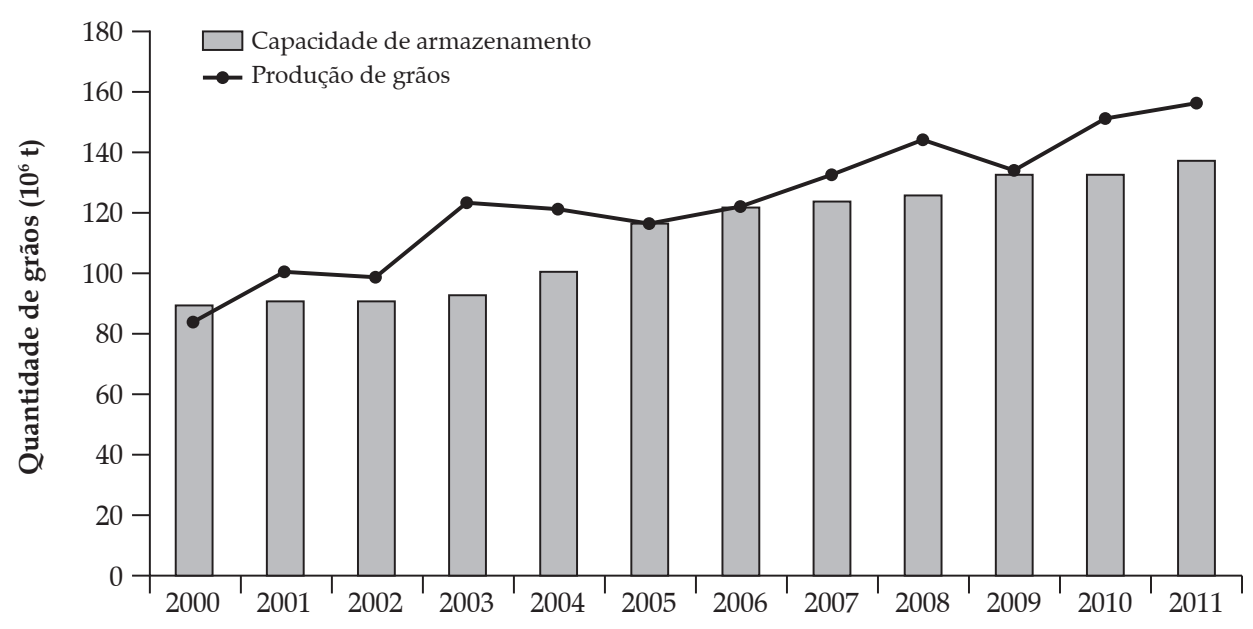

Fonte: Adaptado de Instituto de Econômia Aplicada (IEA, 2014). 
A análise dos resultados das alternativas, quando se leva em consideração apenas o transporte, indica que a melhor opção é vender na entressafra $(0,559)$, pois a demanda por transporte é menor e os preços dos fretes são reduzidos. Quando se avalia pelo ponto de vista da armazenagem, a melhor opção é vender antes ou durante a colheita $(0,417)$, pois neste momento o custo com armazenagem é zero.

\subsubsection{Preço}

O segundo critério identificado como mais importante na determinação do melhor momento de venda de produção de milho foi o preço do produto $(0,281)$, sendo o mercado futuro o subcritério que mais impactou a decisão $(0,528)$. Dessa forma, este torna-se um dos cenários mais seguros para o produtor, o que é evidenciado pelo seu impacto no modelo decisório. Para esse tipo de negociação o contrato exige que o milho seja vendido a granel, com coloração amarela, odor e aspectos normais, bom estado de conservação, livre de impurezas, com umidade de até $14 \%$, produzido na última safra e de origem brasileira e o volume mínimo é de $27 \mathrm{t}$, equivalente a 1 bushel. Este contrato estabelece uma data de pagamento e recebimento futuro de um valor estabelecido no momento da contratação (ADVFN, 2014), o que reduz o risco de incerteza referente ao preço do produto. Este tipo de contratação passa a ser interessante uma vez que, nos últimos anos, o preço das commodities tem sofrido com altos níveis de volatilidade (PERI et al., 2014). Beckmann e Czudaj (2014) utilizaram um modelo econométrico para analisar a variação dos preços das commodities na Bolsa de Mercadorias de Chicago no período de 2000 a 2012 e concluíram que a variação dos preços dos produtos é gerada pela interdependência do mercado futuro, e este comportamento é esperado para os próximos anos. Entretanto, é importante ponderar que, no Brasil, a tentativa de antecipar a venda da commodity em um contrato de mercado futuro é uma tarefa complexa envolvendo a produtividade, o financiamento da produção e o preço dos insumos, entre outros (QUINTINO e DAVID, 2013).
O preço do mercado à vista (spot) da Bolsa de Mercadorias e Futuros tem o segundo maior impacto $(0,333)$. Este valor é estabelecido no início do pregão com base no volume das negociações do dia anterior; ou seja, considera o preço do ajuste, que foi o último valor negociado no dia anterior. Durante o dia, quando o preço do produto oscila, são estabelecidos ajustes diários (SCHOUCHANA, 2004). O preço rege os contratos de venda de milho no mercado futuro. Abitante (2008) fez um estudo comparando o mercado futuro e o mercado à vista para grãos e indica que os valores do mercado futuro, em determinado período, podem ser utilizados como uma forma de se prever o mercado à vista em determinado período do ano. Todavia, os riscos de conseguir preços inferiores permanecem com o produtor.

O terceiro cenário é o valor regional $(0,094)$. Determinou-se por valor regional o preço pago para o produtor em determinada microrregião. Esta análise considera a venda do produto na microrregião produtora que sofre variações de acordo com a produção local, no caso MS. Assim, se houver alta disponibilidade do milho no estado, o preço regional será menor que o preço em outra região ou estado em que a produção for menor, como o Nordeste, por exemplo (SOUSA et al., 2010).

\subsubsection{Produtividade}

O Brasil tem uma das maiores produtividades do mundo, em torno de 18 a 20 t/ha, maior do que a produtividade dos Estados Unidos, que é de 9 a 10 t/ha (ABRAMILHO, 2010). Isso pode explicar o baixo impacto deste na comercialização do produto $(0,162)$. Entre os subcritérios de produtividade, o clima foi fator fundamental na decisão $(0,570)$. O clima tanto pode ocasionar a perda da produção como o aumento da produtividade. Analisando-se as alternativas por meio dos subcritérios da produtividade, encontra-se que, considerando-se o grau de mecanização, a melhor opção é vender o milho durante a colheita $(0,567)$. Considerando-se o clima, a melhor opção é vender durante a colheita ou na entressafra $(0,467)$. E, considerando-se o tipo de solo ou os 
insumos utilizados, estes não influenciam na decisão do melhor momento de venda do milho.

\subsubsection{Disponibilidade do produto}

As comparações paritárias indicaram que a disponibilidade do produto pouco influenciou na decisão do melhor momento da venda $(0,090)$. Todavia, uma das discussões que se faz na comunidade internacional, como pode ser visto nos trabalhos de Ciaian e Kancs (2011) e Dyer (2011), é que a demanda por biocombustíveis altera os preços das commodities, em virtude do aumento da demanda em relação à oferta. Assim, por exemplo, a decisão dos EUA em produzir etanol a partir do milho afetou os preços desta commodity.

Ciaian e Kancs (2011) afirmam que, devido aos preços inelásticos da demanda de alimentos e terra, o preço das commodities agrícolas pode aumentar substancialmente no futuro. As discussões que esta produção de etanol afeta os preços de commodities também tem sido observada em outros países, como o México (DYER, 2011); entretanto, não há consenso dessa influência. Gardebroek e Hernandez (2013) analisaram os preços do etanol e do milho entre 1997 e 2011 e concluíram que não há correlação entre o aumento da produção e do preço do etanol com a variação do preço do milho no mercado norte-americano. Da mesma forma, o estudo anterior de Zhang et al. (2010) também não concluiu a hipótese de que a variação dos preços da commodity estivesse relacionada à maior produção de biocombustíveis.

Concentrando-se no resultado final desse critério, a melhor alternativa do ponto de vista da disponibilidade do produto consiste em vender na entressafra $(0,605)$, justamente no momento em que a demanda é maior que a oferta.

\section{Conclusão}

Os resultados possibilitaram concluir que o melhor momento para a venda do milho é na entressafra; entretanto, os produtores rurais de
Mato Grosso do Sul, cujos dados possibilitaram validar esse estudo, não dispõem de infraestrutura logística disponível para guardar e transportar esse milho durante a entressafra, uma vez que, naquele momento, estão comprometidos com a produção de soja.

O estudo identificou ainda que a logística é o critério que tem o maior peso relativo na decisão de quando comercializar o milho $(0,467)$, que é reflexo do volume de grãos produzidos que exigem áreas de armazenagem e de grande quantidade de transporte para serem movimentados entre os pontos de produção e consumo.

Assim, é possível inferir que o produtor rural pode melhorar sua lucratividade se comercializar o milho na entressafra e se considerar as variáveis logística, preço, produtividade e disponibilidade de produto em conjunto. Entretanto, a logística é o gargalo da operação e afeta diretamente o modelo de decisão, necessitando, assim, estudos complementares sobre a viabilidade de se investir em infraestrutura para comercializar o milho na entressafra.

\section{Referências}

ABITANTE, K. G. Co-integração entre os mercados spot e futuro: evidências dos mercados de boi gordo e soja. Revista de Economia e Sociologia Rural, Brasília, v. 46, n. 1, p. 75-96, jan./mar. 2008.

ABRAMILHO. Associação Brasileira dos Produtores De Milho. A dimensão do milho no mundo. Disponível em: $\quad<$ http://www.abramilho.org.br/noticias. php?cod=975> . Acesso em: 14 mar. 2014.

ADVFN. Entendendo o milho futuro. Disponível em: $<$ http://br.advfn.com/bolsa-de-valores/bmf/milhofuturo/entendendo-o-milho-futuro $>$. Acesso em: 04 abr. 2014.

BECKMANN, J. e CZUDAJ, R. Volatility transmission in agricultural futures markets. Economic Modelling, v. 36, n. 0, p. 541-546, 2014.

CAETANO, M. e PRESSINOTT, F. Custos do frete disparam no início da safra de soja. Disponível em: $<$ http://www.valor.com.br/empresas/3020258/custosdo-frete-disparam-no-inicio-da-safra-de-soja > . Acesso em: 31 out. 2014 
CASTRO, D. M. Políticas públicas e priorização na escolha de modais de transporte para escoamento da produção agrícola Sul-Mato-Grossense. 2014. 96 f. Dissertação (Mestrado em Agronegócios), Universidade Federal da Grande Dourados. Dourados, 2014.

CHINELATO, F. B., CRUZ, D. B. F. e ZIVIANI, F. Made In Brazil: o impacto da infraestrutura da logística brasileira nas operações de comércio exterior. Administração em Diálogo, São Paulo, v. 3, n. 13, p. 44-55, 2011.

CHUN-YU, G. e WEN-LONG, W. An Improved Analytic Hierarchy Process and Application in Grain Production. Journal of Northeast Agricultural University (English Edition), v. 19, n. 2, p. 66-70, 2012.

CIA - Central Inteligence Agency. The world fact book. Disponível em: <https://www.cia.gov/library/ publications/the-world-factbook/geos/br.html > . Acesso em: 14/03/2014.

CIAIAN, P. e KANCS, D'ARTIS. Interdependencies in the energy-bioenergy-food price systems: a cointegration analysis. Resource and Energy Economics, Amsterdam, v. 33, n. 1, p. 326-348, 2011.

CNT - Confederação Nacional do Transporte. Boletim Estatístico. Disponível em: <http://www.cnt.org.br/ Paginas/Boletins_Detalhes.aspx? $\mathrm{b}=3>$. Acesso em: 31 out. 2014.

CONAB - Companhia Nacional de Abastecimento. Acompanhamento. safra brasileira de grãos Safra 2014/15: Oitavo levantamento. Brasília: CONAB, 2015.

CORREA, V. H. C. e RAMOS, P. A precariedade do transporte rodoviário brasileiro para o escoamento da produção de soja do Centro-Oeste: situação e perspectivas. Revista de Economia e Sociologia Rural, Brasília, v. 48, p. 447-472, 2010.

COSTA, H. G. Introdução ao método de análise hierárquica: análise multicritério no auxílio à decisão. Niterói: H.G.C., 2002.

CRUZ JÚNIOR, C. J. et al. O excesso de confiança dos produtores de milho no Brasil e o uso de contratos futuros. Revista de Economia e Sociologia Rural, Brasília, v. 49, n. 2, p. 369-390, 2011.

DELIBERADOR, L.R. et al. Análise de soluções para eliminação das perdas no transporte de soja. In: Congresso Nacional de Excelência em Gestão: 22. 2013, Rio de Janeiro. Anais... Rio de Janeiro: Congresso Nacional de Excelência em Gestão, 2013. 1 CD-ROM.

DENG, X. et al. Supplier selection using AHP methodology extended by D numbers. Journal Service Science, Genebra, v. 1, n. 1, p. 83-98, 2014.
DIVAHAR, S. R. e SUDHAHAR, C. Selection of Reverse Logistics Provider Using AHP. Procedia Engineering, Stockholm, v. 38, n. 0, p. 2005-2008, 2012.

DYER, G. A. e TAYLOR, J. E. The Corn Price Surge: Impacts on Rural Mexico. World Development, Amsterdam, v. 39, n. 10, p. 1878-1887, 2011.

EXPERTCHOICE. Version 11. 2111 Wilson Blvd Suite 763, Arlington, VA 22201, USA. 2014.

FAO - Food and Agriculture Organization. Brasil. Disponível em: <http://faostat.fao.org/site/666/default. aspx>. Acesso em: 19 mar. 2014.

GARCÍA, J. L. et al. Multi-attribute evaluation and selection of sites for agricultural product warehouses based on an Analytic Hierarchy Process. Computers and Electronics in Agriculture, Amsterdam, v. 100, n. 0, p. 60-69, 2014.

GARDEBROEK, C. e HERNANDEZ, M. A. Do energy prices stimulate food price volatility? Examining volatility transmission between US oil, ethanol and corn markets. Energy Economics, Amsterdam, v. 40, n. 0, p. 119-129, 2013.

GOOD, D. Corn Used for Ethanol Production. Disponível em: < http://farmdocdaily.illinois.edu/2013/11/corn-usedethanol-production.html>. Acesso em: 11 mar. 2014.

HONG, L. e XIAOHUA, Z. Study on location selection of multi-objective emergency logistics center based on AHP. Computer Engineering and Intelligent Systems, Genebra, v. 15, p. 2128-2132, 2011.

IBGE-Instituto Brasileiro de Geografia e Estatística. Estados. Disponível em: <http://www.ibge.gov.br/estadosat/perfil. php?sigla=ms\# > . Acesso em: 4 mar. 2014.

IEA - Instituto de Economia Agrícola. Pontos críticos da armazenagem de grãos no Brasil. Disponível em: <http:// www.iea.sp.gov.br/out/LerTexto.php?codTexto $=12111>$. Acesso em: 14 mar. 2014.

IGC - International Grains Council. Five-year global supply and demand projections. Disponível em: <http://www.igc.int/en/downloads/grainsupdate/ IGC_5yearprojections2015.pdf > . Acesso em: 15 dez. 2015.

KURKA, T. Application of the analytic hierarchy process to evaluate the regional sustainability of bioenergy developments. Energy, Amsterdam, v. 62, n. 0, p. 393-402, 2013.

MAPA - Ministério da Agricultura, Pecuária e Abastecimento. Projeções do Agronegócio: Brasil 2012/2013 a 2022/2023. Brasília, 2013. 96 p. 
MARTINS, R. S. et al. Decisões estratégicas na logística do agronegócio: compensação de custos transportearmazenagem para a soja no estado do Paraná. Revista de Administração Contemporânea, Rio de Janeiro, v. 9, p. 53-78, 2005.

MILJKOVIC, D. et al. The barge and rail freight market for export-bound grain movement from midwest to Mexican Gulf: an econometric analysis. Transportation Research Part E: Logistics and Transportation Review, Amsterdam, v. 36, n. 2, p. 127-137, 2000.

MOREIRA, V. R., SOUZA, A. e DUCLÓS, L. C. Avaliação de retornos e riscos na comercialização de milho: estudo de caso usando value-at-risk. Revista de Economia e Sociologia Rural, Brasília, v. 52, n. 2, p. 303-322, 2014.

ONU - Organização das Nações Unidas. World population prospects: the 2015 revision. Disponível em: $<$ http://esa.un.org/unpd/wpp/Publications/Files/Key_ Findings_WPP_2015.pdf > . Acesso em: 14 dez. 2015.

PATINO, M. T. O. et al. Analysis and forecast of the storage needs of soybeans in Brazil. Engenharia Agrícola, Jaboticabal, v. 33, p. 834-843, 2013.

PENG, J. Selection of Logistics Outsourcing Service Suppliers Based on AHP. Energy Procedia, Stockholm, v. 17, Part A, n. 0, p. 595-601, 2012.

PERI, M., VANDONE, D. A. e BALDI, L. Internet, noise trading and commodity futures prices. International Review of Economics \& Finance, Amsterdam, v. 0, n. 0, p. 1-10, 2014.

QUINTINO, D. D. e DAVID, S. A. Quantitative analysis of feasibility of hydrous ethanol futures contracts in Brazil. Energy Economics, Amsterdam, v. 40, n. 0, p. 927-935, 2013.

REIS, J. G. M. et al. The impact of storage strategy in the competitiveness of the Brazilian soybean-complex. In: International Conference of Production Research: 22. 2013, Foz do Iguaçu. Anais... Foz do Iguaçu: International Federation Production Research, 2013. 1 CD-ROM

RFA - Renewable Fuel Association. Ethanol and the US Corn Crop. Disponível em: <http://www.ethanolrfa. org/page/-/objects/documents/1898/corn_use_facts. pdf $>$. Acesso em: 11 mar. 2014.

SAATY. T. L. The Analytic Hierarchy Process. Nova York, NY: McGraw-Hill, 1980.

. Decision making with the analytic hierarchy process. Journal Service Science, Genebra, v. 1, n. 1, p. 83-98, 2008.

. e SHANG, J. S. An innovative orders-ofmagnitude approach to AHP-based mutli-criteria decision making: Prioritizing divergent intangible humane acts. European Journal Operations Research, Amsterdam, v. 214, p. 703-715, 2011.

SALIN, D. Soybean Transportation Guide: Brazil. May 2013. U.S. Dept. of Agriculture, Agricultural Marketing Service, 2013.

SCHOUCHANA, F. Introdução aos mercados futuros $e$ opções agropecuários no Brasil. $3^{\text {o }}$ ed. São Paulo: Bolsa de Mercadorias \& Futuros, 2004

SEPREBOM, P. A. Perdas no transporte agrícola. Monografia (Ciência Política e Desenvolvimento Estratégico), Faculdade Arthur Thomas, Londrina, 2009.

SOUSA, E. P., BRAGA, M. J. e CUNHA, D. A. Interdependência dos preços do milho no sul brasileiro. Revista de Economia, Rio de Janeiro, v. 36, n. 2, p. 71-90, 2010.

SURESHCHANDAR, G. S. e LEISTEN, R. A framework for evaluating the criticality of software metrics: an analytic hierarchy process (AHP) approach. Measuring Business Excellence, Bingley, v. 10, n. 4, p. 22-33, 2006.

USDA - U.S.A. Dept. of Agriculture, Agricultural Marketing Service. AMS. Grain Transportation Report. Washington, 2014.

WORLD BANK. Brazil. Disponível em: < http://data. worldbank.org/country/brazil >. Acesso em: 31 out. 2014.

ZHANG, Z. et al. Food versus fuel: What do prices tell us? Energy Policy, Amsterdam, v. 38, n. 1, p. 445-451, 2010. 
